\title{
GRUPOS DE TRABAJO
}

\section{AC'TIVIDAD DE IOS EQUIPOS DE INVESTIGACIÓN EN DIDÁCTICA DE I,AS CIENCIAS}

Con vistas a realizar un estudio de ámbito europeo, el profesor John Gilbert, editor del International Journal of Science Education, ha solicitado a algunos equipos de investigación en didáctica de las ciencias, mediante un cuestionario ad hoc, una pequeña síntesis de su actividad. Una iniciativa similar está siendo promovida por el profesor Marco A. Moreira para la enseñanza de la física en el ámbito interamericano.

Ambas iniciativas responden a la conveniencia de facilitar los contactos en una comunidad de investigadores en rápida expansión. Hemos creído, pues, converiente, ofrecer las páginas de Enseñanza de las Ciencias para que los distintos equipos de investigación en didáctica den a conocer su actividad, respondiendo, básicamente, al siguiente cuestionario:
1) Nombre del grupo y datos de contacto: nombre del coordinador-a, dirección, teléfono, fax, correo electrónico...

2) Lineas de investigación prioritarias. Incluir la relación de tesis doctorales leídas y en curso.

3) Campos de conocimiento y niveles educativos en los que se centra la investigación diđáctica đesarrollada.

4) Formas de financiación de la investigación.

5) Congresos nacionales e internacionales en los que han participado miembros del grupo.

6) Revistas nacionales e internacionales en las que ha publicado el grupo. Incluir una breve selección bibliográfica de los trabajos publicados.

7) Relación existente entre las investiga. ciones realizadas y la producción de materiales curriculares. Incluir, en su caso, una breve selección de los materiales bibliográficos publicados.

8) Difusión de las investigaciones entre el profesorado en formación y en activo. Incluir, en particular, referencias a las actividades de tipo master, programas de doctorado, etc organizadas por el grupo o en las que participan miembros del grupo.

9) Principales desafios y perspectivas de desarrollo.

10) Relaciones de colaboración con otros grupos nacionales e internacionales.

Puede ser de interés, por último, la inclusión de una breve biografía del grupo, que explique su origen, las formas de vinculación de sus miembros, etc. 